\title{
LOCUCIONES ADVERBIALES DE ÁMBITO JURÍDICO: DE LOS FUEROS MEDIEVALES A SU CONSOLIDACIÓN EN LA LENGUA*
}

\author{
AdEla García VALLE \\ Universitat de València
}

\section{IMPORTANCIA DE LA FRASEOLOGÍA JURÍDICA MEDIEVAL}

Uno de los objetivos de la Fraseología Histórica del español es, sin duda, contribuir a «la elaboración de una historia global de las unidades fraseológicas» ${ }^{1}$, analizando, siempre que sea posible, «la historia particular de cada una de ellas» y aportando cuantos datos se pueda para establecer una periodización en la tipología de estas unidades. Para alcanzar este propósito, resulta necesario atender a la fraseología jurídica medieval, ya que este tipo de lenguaje técnico es una buena fuente de unidades fraseológicas, tanto de fórmulas como de locuciones adverbiales, que son las que aquí nos ocupan. En concreto, interesa conocer cuáles son las locuciones adverbiales que aparecen en los fueros con el fin de poder compararlas con las de los documentos notariales, por un lado, y para tener una visión global de las unidades fraseológicas propias de la lengua jurídica en la Edad Media, por otro.

El estudio aquí presentado se centra en un tipo determinado de unidades fraseológicas, las locuciones, y, más concretamente, las adverbiales, así llamadas por ser producto de una lexicalización equivalente a la categoría adverbial ${ }^{2}$,

\footnotetext{
* Este trabajo se inscribe dentro del Proyecto de Investigación: Historia, codificación y fijeza de las locuciones adverbiales en un segmento temporal del español (1492-1596), -referencia HUM2005-02879/FILO-, dirigido por M. ${ }^{a}$ T. Echenique y subvencionado por el M. de Educación y Ciencia.

${ }^{1}$ M. $^{a}$ Teresa Echenique Elizondo, «Algunas notas sobre latín y romance en la fraseología hispánica medieval», Eighth Internacional Late and Vulgar Latin Conference (septiembre de 2006, Oxford, St Catherine's College), 2008, pág. 540.

2 De la reflexión de Gómez Asencio acerca del concepto de locución en la «tradición gramatical» española, se desprende una definición bastante precisa de las locuciones adverbiales (José Jesús Gómez Asencio, «De las locuciones ¿Qué se hizo en la tradición gramatical española?», Interlingüística, 14, 2003, pág. 59).
} 
con el objeto de conocer el proceso histórico que ha permitido su fijación formal y semántica ${ }^{3}$.

\section{UNIDAD FRASEOLÓGICA. LOCUCIÓN ADVERBIAL}

La definición de unidad fraseológica ha sido tratada por varios autores ${ }^{4}$ y puesto que un estudio de estas características requiere plantear con claridad la concepción de este tipo de unidad, vamos a seguir aquí, por las consideraciones tan acertadas que presenta, la propuesta de Montoro del Arco, para quien las unidades fraseológicas

son segmentos lingüísticos pluriverbales (formados por dos o más palabras gráficas) cuyos elementos componentes han perdido parte de sus propiedades paradigmáticas y sintagmáticas propias (que pueden seguir manteniendo en otros contextos) y que se comportan como una unidad institucionalizada: en el plano morfosintáctico, manifiestan un determinado grado de fijación formal, y un determinado grado de variación potencial fija; desde el punto de vista semántico, presentan un determinado grado de idiomaticidad o especialización semántica; desde el punto de vista pragmático, se caracterizan por haber adquirido valores que afectan especialmente a alguna de las instancias de la comunicación: relación interactiva (cortesía, etc.), relación entre las partes del discurso (conexión) o actitud del hablante ante el discurso (modalidad). Cada una de ellas se define, además, por una función que puede hallarse dentro del marco estructural o bien en un marco discursivo 5 .

Y, por lo que se refiere a las locuciones, consideradas como un subtipo dentro de las unidades fraseológicas, compartimos las opiniones de Casares, Zuluaga, Corpas, Ruiz Gurillo, Penadés, etc., recogidas ahora por Montoro del Arco, al señalar que se caracterizan por la función autónoma que cumplen en el interior del enunciado y, además, por «ser pluriverbales y tener algún grado de fijación, variación potencial fija y especialización semántica, esto es, idiomaticidad» ${ }^{6}$. Conviene tener en cuenta que todos los rasgos que caracterizan a las

${ }^{3}$ Estamos, pues, de acuerdo con Montoro del Arco en que un análisis histórico detallado de la formación de las expresiones fijas redundaría favorablemente en una apreciación más adecuada de la fijación y de las posibilidades de variación (Esteban Tomás Montoro del Arco, Teoría fraseológica de las locuciones particulares. Las locuciones prepositivas, conjuntivas y marcadoras en español, Frankfurt am Main, Peter Lang, 2006, pág. 42).

${ }^{4}$ Gloria Corpas, Manual de fraseología del español, Madrid, Gredos, 1996. Leonor Ruiz Gurillo, Las locuciones en español actual, Madrid, Arco/Libros, 2001, pág. 15, etc.

5 Esteban T. Montoro del Arco, Teoría fraseológica..., op. cit., págs. 110-111. Los requisitos mínimos característicos de las unidades fraseológicas se presentan en las págs. 39-67.

${ }^{6}$ Esteban T. Montoro del Arco, Teoría fraseológica..., op. cit., pág. 273. Recoge opiniones previas como las de Julio Casares (Introducción a la lexicografía moderna, Madrid, CSIC, 1950), Alberto Zuluaga Ospina (Introducción al estudio de las expresiones fijas, Tübingen, Max Hueber, Verlog, 1980), Gloria Corpas (Manual de fraseología del español, op. cit.), Inmaculada Penadés 
locuciones, tales como la fijación, la idiomaticidad y otros, se consolidaron formalmente en etapas anteriores de la lengua?

Así pues, uno de los rasgos definitorios de las locuciones es su fijación o estabilidad formal. Contreras y Súñer reconocen la importancia de esta característica al explicar que tanto la lexicalización, concebida como un procedimiento de creación de nuevos elementos léxicos, como la gramaticalización «son procesos diacrónicos que comparten algunos efectos como la fijación gramatical de los elementos afectados, la pérdida o modificación de su significado primigenio o su recategorización ${ }^{8}$. Ahora bien, vamos a comprobar si, como dice Montoro del Arco, a propósito de la fijación, «no todas las Ufs tienen los mismos grados de fijación» y «las causas de la fijación formal hay que buscarlas en el capricho del uso forjado a través de la historia de la lengua, pues una misma estructura no garantiza un comportamiento similar» ${ }^{9}$.

Asimismo, en el estudio histórico de las locuciones adverbiales, además de atender al proceso de inmovilización de estas unidades, resulta necesario considerar otros factores entre los que destaca la inserción de estas combinaciones sintagmáticas en determinadas tipologías textuales, tales como los textos jurídicos, objeto de atención en este estudio.

Por lo que respecta a la clasificación de las locuciones, las propuestas de diferentes autores se centran bien en sus características internas (Zuluaga, Ruiz Gurillo), bien en la categoría léxica a la que sustituyen (Casares, Zuluaga, Corpas, Ruiz Gurillo). Dentro de los dos grupos de locuciones que establece Montoro del Arco, las adverbiales se incluyen en el de

aquellas cuya función semántica tiende a ser REFERENCIAL, conceptual o nocional y que, en consecuencia, tienden a la lexicalización, esto es, a ser categorizadas como clases de locuciones equivalentes a las clases de palabras «plenas»; suelen saturar huecos funcionales primarios en la oración [...]. Desde el punto de vista pragmático, pueden manifestar los distintos valores que se resumen con el concepto de expresividad (intensificación, diferencias diastráticas, etc. $)^{10}$

(La enseñanza de las unidades fraseológicas, Madrid, Arco-Libros, 1999) o Leonor Ruiz Gurillo (Aspectos de fraseología española, Valencia, Cuadernos de Filología, 1997, y Las locuciones en español actual, op. cit., pág. 25).

${ }^{7}$ Así opinan entre otros Zuluaga, Ruiz Gurillo, Echenique, etc.

8 Joan Miquel Contreras, y Avel-lina Súñer, «Los procesos de lexicalización», en Pérez Gaztelu, Zabala y Gràcia, eds., Las fronteras de la composición en lenguas románicas y en vasco, San Sebastián, Universidad de Deusto, 2004, págs. 60-86. Otros autores se refieren a la fijación en términos de 'inmovilización', tal como hace Bosque (Ignacio Bosque, «Sobre el concepto de 'lugar común' desde el punto de vista gramatical», Lieux Commmuns/Pandora. Revue d'Études Hispaniques, 1, 2001, Université de Paris 8, 2001, págs. 31-45), o 'fijeza', en palabras de Seco (Manuel Seco et alii, Diccionario fraseológico documentado del español actual, Madrid, Aguilar, 2004).

${ }^{9}$ Esteban T. Montoro del Arco, Teoría fraseológica..., op. cit., pág. 42.

${ }^{10}$ Esteban T. Montoro del Arco, Teoría fraseológica..., op. cit., pág. 274. 


\section{LAS LOCUCIONES ADVERBIALES DE LOS FUEROS MEDIEVALES}

El estudio de las locuciones que va a llevarse a cabo recogerá, en primer lugar, las unidades que conforman el corpus de análisis, aportando cuantos datos sea posible para avanzar en la historia particular de cada una de ellas. Se va a intentar, en segundo lugar, delimitar las combinaciones sintácticas más productivas y que con mayor frecuencia forman locuciones adverbiales en los fueros medievales. Se tratará, en tercer lugar, de averiguar el alcance de estas locuciones propias de los fueros para conocer su proyección más allá del ámbito foral; para ello serán comparadas y contrastadas, siempre que sea posible, con las locuciones adverbiales encontradas en los documentos notariales, analizando lo que tienen en común, así como las divergencias entre estos dos tipos de lenguaje jurídico. Asimismo, se contrastará, en la medida en que haya posibilidad, las unidades de la scripta castellana con las de otras scriptae peninsulares con el fin de valorar los datos que pueden desprenderse de su consideración.

Este análisis se centra, pues, en el estudio de las locuciones adverbiales que destacan en varios fueros medievales con la finalidad de aportar una visión lo más completa posible de la presencia, uso y evolución de las locuciones adverbiales, tanto en su contexto foral concreto, como en el más amplio del lenguaje jurídico.

Pues bien, al estudio de las locuciones adverbiales en documentación notarial medieval de la primera mitad del siglo XIII ${ }^{11}$, se va a añadir el que se pretende extraer y presentar en este trabajo a propósito de diversos fueros medievales $^{12}$ de gran relevancia lingüística. Son los siguientes. En primer lugar, los fueros leoneses de Zamora, Salamanca y Ledesma ${ }^{13}$. En segundo lugar, el Fuero de Úbeda ${ }^{14}$, que debió de escribirse hacia 1251. En tercer lugar, se ha

11 Adela García Valle, «Las locuciones adverbiales en la documentación notarial medieval», en C. Company Company y J. G. Moreno de Alba, eds., Actas del VII Congreso Internacional de Historia de la lengua española (Mérida, México, 2006), Madrid, Arco/Libros, 2008, vol. I, págs. 593-611.

12 Adelantamos aquí que van a respetarse las normas de edición de cada uno de los fueros estudiados para conformar el corpus de referencia de este trabajo.

13 Américo Castro y Federico de Onís, eds., Fueros leoneses de Zamora, Salamanca, Ledesma y Alba de Tormes, Madrid, Centro de Estudios Históricos, 1916. La edición del Fuero de Zamora, ordenanza confirmada por el rey de León Alonso IX en enero de 1208, se hizo teniendo en cuenta tres manuscritos de la Edad Media, pero dando preferencia al más antiguo, el MS Q en el que se menciona la fecha de 1289. En la edición del Fuero de Salamanca también se tuvo en cuenta los tres manuscritos medievales, sobre todo, el más antiguo «por el carácter de la letra, por la ortografía y por el lenguaje» (pág. 74). De este fuero se sabe que el MS A es el más antiguo y el MS C es una refundición más tardía. La edición del Fuero de Ledesma se hizo atendiendo al único manuscrito conocido, posterior a la versión C del de Salamanca, ya que una gran parte de su contenido «procede del Fuero de Salamanca, del cual fue copiada literalmente, a veces con modificaciones más o menos importantes» (pág. 213).

14 Mariano Peset, Juan Gutiérrez Cuadrado y Josep Trenchs Odena, eds., Fuero de Úbeda, Valencia, Servicio de Publicaciones de la Universidad, 1979. El manuscrito al que se atendió 
atendido al Fuero de Madrid ${ }^{15}$, que se fecha hacia 1202. Por último, se ha revisado también el Fuero de Alcalá ${ }^{16}$, que, en opinión de la editora, debe situarse hacia 1235.

Estas son las principales locuciones adverbiales halladas en los textos forales revisados. Las presentamos con grafía normalizada y, por razones de espacio, no se van a mostrar ejemplos de todas sus variantes gráficas, aunque sí se van a señalar:

\subsection{En paz}

En el Fuero de Madrid, esta locución, bastante frecuente, aparece en latín, in pace, con una variación gráfica, in paze, al menos en ocho ocasiones, formando parte de una fórmula tan sólo una vez, en el primero de los ejemplos que se presentan a continuación. En el Fuero de Úbeda se presenta unas cuatro veces, en casos como dexele en paz (pág. 348), vaya en paz (pág. 383) y en otros ejemplos:

Hec est carta quem facit concilium de Madrid ad honorem domino nostro rege Alfonsus et de concilio de Madrid, unde diues $\tau$ pauperes uiuant in pace et in salute (Madrid, pág. 29)

E sy aquel que enemigo fue ante que Ubeda fuese presa vinjiere poblar a Ubeda \& fallare y su enemigo, den amos fiadores de saluo a fuero de Ubeda que sean en paz. (Úbeda, pág. 256)

\subsection{Por fuero, a fuero, en fuero}

Prácticamente en todos los fueros se encuentra esta locución, en latín y en romance, con variaciones como per foro, per (suum) forum, per fuero y por (este) fuero. También hay variantes en cuanto a la preposición que introduce la locución, ya que en el Fuero de Alcalá se halla en fuero y en el de Úbeda junto a por fuero, que aparece en diecinueve ocasiones, y su variación por este fuero, en dos, se encuentra también a fuero, unas seis veces. Por fuero se muestra ocho veces en el Fuero de Madrid, cinco en el de Salamanca, una en

para su edición debe datarse durante «la primera mitad del siglo XIV, ya que los elementos paleográficos, históricos y lingüísticos así lo confirman» (pág. 240). En algunos manuscritos de este texto, perteneciente a la familia conquense, «ha intervenido la Biblia, el derecho romano, la tradición oral, las fazañas, etc.» (pág. 33).

${ }^{15}$ Galo Sánchez, El Fuero de Madrid y los derechos locales castellanos, Madrid, Publicaciones del Archivo de Villa, 1932. En cualquier caso, puesto que se redactó con seguridad durante el reinado de Alfonso VIII, habría que encuadrar la fecha del texto entre 1158 y 1214 (pág. 16).

${ }^{16}$ M. ${ }^{a}$ Jesús Torrens Álvarez, Edición y estudio lingüístico del Fuero de Alcalá (Fuero Viejo), Alcalá de Henares, Fundación Colegio del Rey, 2002. Se trata de un documento oficial que no presenta datación crónica ni tópica, pero, al saber que fue otorgado por Rodrigo Jiménez de Rada, arzobispo de Toledo, tal como viene avalado por su firma, se sitúa cronológicamente en la primera mitad del siglo XIII, con anterioridad a 1247, fecha de la muerte del arzobispo. 
el de Zamora y cuatro en el de Ledesma, donde también se repite como locución la variante a fuero (quince veces) con alternancia de preposición:

A lo que me enbiaste dezir del que era vençido por fuero quel manda morir; \& non dyzen por grant furto o por pequenno, a esto digo que se libre según derecho \& non por este fuero (Úbeda, pág. 409)

Mas aquel que sobre la sennal non quisiere sallir a fuero, prendal su contendor cada dia sin calonna fasta que salga a fuero (Úbeda, pág. 333)

$\tau$ quando Regi $ح$ concilio non placuerit, uiuant per suum forum (Madrid, pág. 55)

Qui omne matar, peche C morauedis, si non es enemigo sacado por foro. Qui matar enemigo [sacado] por fuero, quilo quesier amparar, si more le hy auenier, non salga enemigo ni peche coto (Salamanca, pág. 81)

Iuyzes que fueren en Çamora, per fuero lieuen ela senna de conceyo (Zamora, pág. 49)

En el $C O R D E^{17}$ se recogen numerosas entradas de la locución en fuero desde 1200 hasta al menos 1753, en expresiones como es establecido en fuero; do a vos en fuero; assí como en fuero; para siempre iamás en fuero; y en ocasiones formando parte de fórmulas como en estos casos: sabidores en fuero e en derecho; e con otros omnes buenos sabidores en fuero e en derecho; han de mantener la tierra en fuero \& en derecho, etc. A propósito de fuero, en el $D C E C H$ se explica que

el significado originario en castellano es 'lo conforme a la justicia', 'el derecho' [...]. De ahí se pasó, concretando a 'compilación de leyes' (Fuero Juzgo), más especialmente 'código privativo de un municipio; y, por otra parte, conservando la ac. abstracta, 'jurisdicción, competencia a que está sometido alguien conforme a derecho' [...]. FǑRUM sólo se ha conservado como término popular, en su sentido jurídico, en castellano y en el port. foro, también algo en catalán y occitano medievales [...]. Como duplicado culto, foro 'jurisdicción para sentenciar causas', 'los tribunales'...18

Atendiendo a estas precisiones, parece que estas locuciones mantienen el significado originario de 'en conformidad a la justicia', y, sobre todo, porque no se trata de una expresión ocasional, sino que, como ya hemos visto en el CORDE, se repite a lo largo del tiempo, formando parte de fórmulas en algunas ocasiones. Mantiene, además, aun en textos redactados en romance, la forma más próxima al latín, foro, lo que redunda en la idea de supervivencia de arcaísmos gráficos jurídicos, junto a otros casos en los que, al igual que en los ejemplos del CORDE, se presenta siempre con su forma romance, fuero. Y en

${ }^{17}$ Real Academia Española, Corpus de Referencia Diacrónica del Español. CORDE. En http://corpus.rae.es/cordenet.html.

${ }_{18}$ Joan Corominas y José Antonio Pascual, Diccionario crítico etimológico castellano e hispánico, t. II, Madrid, Gredos, 1991 [1980], pág. 971. 
diversos casos parece que la alternancia entre las preposiciones podría deberse a una cuestión de régimen verbal ${ }^{19}$ (salir a fuero, saber en fuero, etc.).

\subsection{Por fuerza, a fuerza, con fuerza}

Por fuerça, con las variantes y variaciones gráficas por (su) forcia, per(la) forza, per forcia, a forcia y con forza, es también una locución adverbial frecuente en los fueros. En el de Úbeda no presenta variaciones, se halla en once ocasiones, siempre con la preposición por. En el Fuero de Madrid se encuentra al menos en cuatro ocasiones, en el de Salamanca en cinco, en el de Zamora en dos y en el de Ledesma en siete, en algunas de ellas parece formar parte de una fórmula:

Todo omne de Madrid que intrare con forza ₹ cum uirto $ح$ con armas, de dia aut de nocte per superbia in casa de uecino, $\tau$ ibi matare el senor de la casa aut dona de la casa uel filio de casa aut alguno de suos parentes [...] pectet $\mathrm{C}$ morabetinos... (Madrid, pág. 32)

Qui pesquera ayena deffeçier auirto o aforcia, o heredade ayena, con armas, peche X morauedis, e elos obreros V V morauedis (Salamanca, pág. 132)

Omne que heredade demandar oauer e nola demandar en uida del quela touier e non prindar por ella e non ayu[i]zar, e despues de sua muerte non respondan della fillos $\mathrm{n}[\mathrm{e}]$ muller, foras atanto de firma[r] el que la demanda con V omes bonos que per forcia e por torto la tenia; e respondale de la (Zamora, pág. 27)

Qualquier que al cauallero desçendiere del cauallo por fuerça peche quinjentos sueldos, sy el cauallero firmar pudiere (Úbeda, pág. 308)

\subsection{Por derecho, a derecho, con derecho}

La locución adverbial por derecho, con las variantes a derecho y con derecho, también es bastante frecuente en algunos fueros. En el de Ledesma se encuentra en trece ocasiones, de las cuales tan sólo dos con la preposición por y todas las demás con la preposición $a$. Y, aunque podría tratarse en este caso de una característica particular, la preferencia por la preposición $a$ en esta y en otras locuciones, como en el caso de a fuero, a fuerza, a sabiendas, etc., posiblemente deba tratarse de una característica general porque parece compartirla con los fueros de Salamanca y de Alcalá. En este último, a derecho se encuentra al menos en catorce ocasiones y en una alterna con per derecho. En el Fuero de Salamanca (diecisiete veces) domina la variante con la preposición $a$, ya que tan sólo tres presentan la preposición por, una la preposición con y asimis-

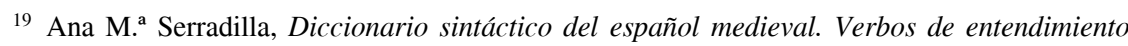
y lengua, Madrid, Gredos, 1996. 
mo en una ocasión aparece la variante a derecha. En el Fuero de Zamora, junto a la variante $a$ derecho, que también es la más frecuente, cuatro veces, se da por derecho una sola vez. En el Fuero de Úbeda es tan frecuente la variante $a$ derecho (cuatro veces) como por derecho (cuatro veces). Ejemplos:

Todo omne qui demandare a otro omne: «dadme vuestro omne a derecho», diga 1 so nombre e déll a derecho si con el fore, e si·l encamparen o disiere: «non es mio omne», jure que non como so pan ni non faze so mandado, e si non quisiere jurar déll a derecho (Alcalá, pág. 495)

... e si algún omne tomare carnero en el coto e non pudiere essir con él per derecho, el vivo tórnelo vivo e el morto tórnelo duplado, e vala medio moravidí (Alcalá, pág. 500)

E elos ueladores, quando entraren, iuren en conceyo que lo fagan a derecha como aquí es escripto (Salamanca, pág. 110)

E el conceyo de Salamanca, que lo ampare con derecho (Salamanca, pág. 202)

\subsection{A yuso, de yuso. De suso, a suso...}

En cuanto a la categoría gramatical de a yuso, a suso, de yuso, de suso, etc., consideramos que se trata de locuciones adverbiales por su función autónoma, por el grado de fijación que presentan, junto a la variación potencial fija, y por su especialización semántica. Así pues, en todos los casos se trata de sintagmas formados por una preposición seguida de un adverbio y sus significados difieren en ocasiones del que se obtiene de la simple suma de los significados de sus elementos componentes. Si bien es cierto que a yuso parece estar más cerca del carácter plenamente adverbial, la presencia de las otras locuciones, junto con las variaciones que presenta, hace que haya que decantarse por considerar que se trata de una locución adverbial. Así pues, la locución a yuso se encuentra en varios fueros. En el de Madrid destaca la variante gráfica ad iuso, que permite comprobar el antecedente latino, a veces también reforzada con inde, esto es, inde adiuso e inde en aiuso. En el Fuero de Salamanca se recoge en siete ocasiones ayuso, de las cuales una se presenta como dende ayuso. También se encuentra ayuso en el Fuero de Ledesma en cinco ocasiones, sin variantes gráficas ni variaciones. En el Fuero de Úbeda aparece a yuso cuatro veces, dos de yuso, una de ellas con la variación gráfica de diuso, y tres la locución formada por dos preposición ante el adverbio, esto es, de ayuso. En el Fuero de Alcalá, la locución de yuso, y sus variantes, las locuciones en ayuso y dende ayuso, así como de suso se encuentran en varias ocasiones, por lo menos en diez ejemplos. A / de suso aparece cinco veces en el Fuero de Zamora, y en el de Úbeda se halla siempre de suso, veintiocho veces. De suso y de yuso se encuentran igualmente en documentos notariales, aunque no las otras variantes de estas locuciones, que parecen más propias del registro foral. Ejemplos: 
Toto homine qui calumpnia habuerit a pectare alos fiadores, $\tau$ non habuerit unde pectare, de duos morabetinos ariba, corten suas oreias, $\tau$ de duos morabetinos ad iuso, mittant eum in zepo, usque pectet suo hauer uel sedeat suo pazere (Madrid, pág. 33)

Et ubi cadit el arroio de Tocha en Balnegrar, inde en aiuso (Madrid, pág. 39) En cabana de uacas ne de oueyas no aya mas de V mancebos aportalados, o dende ayuso (Salamanca, pág. 146)

Et onde el omne muerto fuer, parientes del muerto connobren quatro delos dela lide o delos dela buelta, o de IIII ayuso quantos quisieren (Ledesma, pág. 216)

\& sean tan altos que la mano de diuso pueda meter la que a saluar se oujere (Úbeda, pág. 303)

Ca muchas vezes suele acaesçer que los moljnos de ayuso enpesçen a los de suso por grant abondança de agua (Úbeda, pág. 281)

Todo omne d'Alcalá qui demandare a otro de III soldos en ayuso non faga mancuadra,... (Alcalá, pág. 507)

Qui en buelta crebantare dient ad otro omne, los IV delante, los II d'iuso e los II de suso, al dente peche C sueldos,... (Alcalá, pág. 469)

Ese elos iuyzes ouieren enquisa de $\mathrm{V}$ omnes bonos asuso que lo mato, fagan de so cuerpo iusticia selo podieren pre[n]der (Zamora, pág. 22)

\subsection{Por bien, a bien}

La locución por bien, tan frecuente en la lengua foral como en la notarial, aparece en seis ocasiones en el Fuero de Salamanca, una en el de Ledesma y en el de Alcalá y trece en el de Úbeda, en el que también se recoge en una ocasión a bien. Ejemplos:

Esto vio el arçobispo don Martin por bien con bonos omnes del concejo por el mayordomo del castellano,... (Alcalá, pág. 493)

$\&$ sy en la cuenta vieren que mas amengua que non lo acreçe, tulganle el njnno \& el auer e dengelo aquel que entendieren que lealmente leuara el pegujar a bien (Úbeda, pág. 292)

\subsection{Por ende}

Esta locución adverbial se encuentra en varios fueros, en el de Salamanca se muestra en una ocasión, en el de Ledesma en diez, en el de Zamora una vez, $\mathrm{y}$ en el de Úbeda en dieciocho ocasiones. Su variante latina pro inde aparece siete veces. Las variaciones por inde y per inde se encuentran en el Fuero de Madrid:

E si por ende algun omne le demostrar mal querencia, peche CCC soldos (Salamanca, pág. 140).

Qui forzauerit mulierem, moriatur proinde (Madrid, pág. 54) 
Et si apreciado non fuerit, por inde non perdat suo coto;... $ح$ iure dono de la uinea quod lo priso in sua uinea, $ح$ per inde lo mato, ح ibi iazeat (Madrid, pág. 39)

En esta locución se presenta una palabra diacrítica, ende. A propósito de estas palabras, señalan Contreras y Súñer que "el carácter diacrónico de la lexicalización explica que hayan quedado engarzadas en ciertas locuciones palabras que actualmente han caído en desuso o que no tienen sentido aisladas de la construcción lexicalizada ${ }^{20}$.

Así pues, en la locución por ende se puede apreciar como «una palabra perteneciente al léxico común va siendo desplazada del uso diario por razones de cambio léxico, en tanto queda fijada en una unidad fraseológica determinada como palabra diacrítica o idiomática ${ }^{21}$, y, como tal, llega hasta la actualidad, aunque

teniendo en cuenta que el étimo de por ende es latín PROǏNDE [...], indica que se habría producido ya el análisis de por ende por influencia probable del derivado castellano ende < INNDE, Nebrija documenta la locución como un solo vocablo porende, lo que apunta a que considera porende conjunción unitaria y no compuesta a partir de la voz simple ende [...]. Nebrija no participa aún de la nueva consideración escindida de por ende, como es ya la nuestra y como probablemente lo es desde tiempo atrás, después de que se hubiera perdido la primitiva lexicalización, por reanálisis ayudado por la existencia de ende $e^{22}$.

\subsection{Por onde}

Esta locución adverbial se encuentra en el Fuero de Alcalá en dos ocasiones, así como en los de Salamanca, Ledesma y Úbeda. Onde es un nexo desaparecido en el paso del castellano medieval al español clásico y también desapareció por onde. Ejemplos:

Alcalde o iusticia que penos atreguare, por onde los mesquinos pierdan derecho, si non fore por mandado de cabildo, el alcalde ola iusticia que lo feziere peche la peticion que demanda el mesquino (Salamanca, pág. 124)

Otrosi, vezino nunca se despida de la collaçion fasta que toda la debda sea pagada por onde la collaçion fuere adebdada, él seyendo vezino (Úbeda, pág. 313)

\footnotetext{
${ }^{20}$ Joan M. Contreras, y Avel-lina Súñer, «Los procesos de lexicalización», art. cit., pág. 89.

${ }^{21} \mathrm{M}^{\mathrm{a}}{ }^{\mathrm{T}}$ Teresa Echenique, "Algunas notas sobre latín y romance en la fraseología hispánica medieval», art. cit., pág. 543.

${ }^{22}$ Ibíd.
} 


\subsection{En arriba, a arriba}

Se trata de dos locuciones muy frecuentes. En el $D C E C H$ se explica, a propósito de la palabra riba que «en cast. (...) el vocablo tiende a quedar estereotipado en locuciones inseparables o en la toponimia». Estas locuciones se hallan en el Fuero de Alcalá: en arriba (cuatro veces), ad arriba (tres veces) y a arriba (una vez). También en el de Madrid, con variaciones gráficas como en ariba y ad ariba. Por ejemplo:

Todo omne de Alcalá qui oviere molino párese in la canal e eche cual piedra quisiere ad arriba con so mano,... (Alcalá, pág. 474)

E de I moravidí arriba con II bezinos por cuanto jurare el señor fasta valía de $\mathrm{X}$ moravidís e péchelos; e de X moravidís ad arriba con VI bezinos (Alcalá, pág. 502)

Júdez, o alcaldes, o fiadores plegadores o andadores, por pendra que fizieren seyendo en el portiello non respondan de carrestoliendas arriba e si antes no los prendaren non recudan;... (Alcalá, pág. 496)

Toda panedera a que falaren pan minguado, de III panes en ariba pectet medio morabetino (Madrid, pág. 43)

Qui tripas lauare del alcantariella de Sancti Petri ad ariba, pectet I octaua de morabetino a los fiadores (Madrid, pág. 48)

Si bien parecen variantes de una misma locución adverbial, se están utilizando con significados distintos, dado que en arriba presenta un evidente valor de cantidad, mientras que ad arriba se utiliza sobre todo como locución adverbial de lugar, aunque a veces también permite expresar bien cantidad, bien tiempo como en el caso de de Sancti Petri ad ariba. Aún es más, en algunas ocasiones arriba aparece en los mismos contextos que $a(d)$ arriba, tal vez con la preposición $a$ embebida por fonética sintáctica. Ello parece ocurrir en el caso de la expresión temporal de carrestoliendas arriba, sin continuidad en la lengua por lo que no puede considerarse como locución adverbial.

En arriba se forma con la preposición en al igual que en guisa, en alto, en gordo... y, en el caso de en a yuso, precediendo a otra preposición. De esta manera, se puede ver como el sintagma formado con en + sustantivo, adjetivo o adverbio es uno de los procedimientos de creación de locuciones en la lengua foral. Además, podría pensarse que la $a$ de a yuso se presenta por analogía con la $a$ de arriba.

\subsection{Dende adelante y dende arriba}

Estas dos locuciones se encuentran en los fueros de Úbeda y de Alcalá en varias ocasiones, con algunas variantes en el último como dend(e) / den / deinde arriba. 
En cuanto a la categoría gramatical de dende ${ }^{23}$, destaca una vez más, al igual que en el caso de a yuso, la dificultad para clasificar estos elementos por la gran variedad de valores semánticos y funciones del sistema preposicional medieval en competencia directa con los del sistema adverbial ${ }^{24}$. En el caso de dende, consideramos lexicalizada como adverbio la forma antigua de prep. + adv. (de ende $)^{25}$. Así parecen confirmarlo los ejemplos encontrados en los textos forales medievales. Igualmente, adelante y arriba se presentan con un carácter plenamente adverbial en los fueros medievales, de manera que la unión de dos adverbios se constituye en otro mecanismo de creación de locuciones adverbiales en la lengua foral, al igual que el sintagma constituido por preposición seguida de adverbio como en arriba, por ende, de yuso, para siempre, etc.

Sy el debdor en rrecua o a otras mercaduras quisier yr o al rrey, \& ante que salga el querelloso lo pudiere testiguar con tres vezinos o con dos alcaldes, diziendol quel pague, \& él se fuere, el querelloso prende cada dia dende adelante en casa del debdor... (Úbeda, págs. 347-348)

Todo omne de Alcalá o de so término qui oviere cavallo que vala XV moravidís o dende arriba e morare in villa... excuse pecha e non peche (Alcalá, pág. 473)

Deinde arriba, los omnes que oviere opus el pastor, el pastor los coja... (Alcalá, pág. 489)

\subsection{En (tal) guisa, por tal guisa}

Con la palabra guisa se hallan las siguientes locuciones adverbiales: en tal guisa, en el Fuero de Zamora, por tal guisa, en el de Salamanca, y en guisa en el de Alcalá:

E aquel que ueniere por dar derecho, uenga en tal guisa apareyado como cunpla atal derecho, qual mandaren elos iuyzes (Zamora, pág. 19)

Todo omne que alguna cosa mandar asu pariente o asu amigo o asu uezino por buen amor, por tal guisa lo mande quelelo de (Salamanca, pág. 93)

Todo omne de Alcalá o de so término qui fore cativo, o fore in romería o fore enfermo en guisa que non va a el iglesia o a mercado o non fuere de días o fore enemigo, non perda respusa per hereditate por año e día (Alcalá, pág. 471)

23 De inde (deinde) se recoge en el CORDE desde el año 780 ininterrumpidamente hasta 1970 al menos, en numerosos escritos, todos en latín, principalmente documentos notariales.

${ }^{24}$ Carlos Sánchez Lacis, «Omisión y adición de la preposición de en construcciones sintácticas del español medieval y clásico», Actas del VI Congreso Internacional de Historia de la Lengua Española (Madrid, 2003), t. II, Madrid, Arco-Libros 2006, pág. 1087.

25 Ya en latín se trataba como adverbio la forma DENDE. Asimismo, como forma adverbial plena parece considerarlo Eberenz, para quien el valor etimológico de ende lo cubría también dende en la etapa medieval (Rolf Eberenz, «Cambios morfosintácticos en la Baja Edad Media», en Cano Aguilar, coord., Historia de la Lengua Española, Barcelona, Ariel, 2004, pág. 618). 
De la locución adverbial en guisa se encuentran también innumerables ejemplos en el CORDE, desde finales del siglo XII hasta al menos el último cuarto del siglo XX, siempre en escritos en romance, algunos de ellos jurídicos, pero no exclusivamente.

\subsection{A vuelta, de vuelta}

La locución adverbial a vuelta, con la variante de vuelta, se halla en dos fueros, el de Salamanca y el de Ledesma. Se recoge, junto con a vueltas, en el $D R A E$ de 1933, con el significado de 'juntamente, además'26, de ahí que deba considerarse como locución:

Eparientes del muerto, depues que ouieren sacados sus enemigos, saluent se todos los otros de buelta, cada uno con XII omnes aiura (Salamanca, pág. 78) Todo omne que sacare armas abuelta, si ouiere otorgamiento de III omnes ode una iusticia, peche V morauedis; e si non, iure si tercero (Salamanca, pág. 96)

\subsection{Sin grado, de grado, a grado}

La locución sin grado y su variante sin su grado aparecen en los fueros de Alcalá (sin grado en una ocasión y sin so grado en dos), Salamanca y Ledesma. El DRAE señala que se trata de una locución adverbial antigua, con el mismo significado que de mal grado, esto es, 'sin voluntad, con repugnancia y a disgusto' ${ }^{27}$. La locución de grado se halla en el Fuero de Alcalá, una vez, y en el de Úbeda con determinante, de su grado, y con la variante a su grado; siempre con el significado de 'por propia voluntad':

E si al rio entrar ela riba del brazo passar, sea arrancado, si non pudier que el cauallo lopasso el rio alende sin grado (Salamanca, pág. 113)

E delas moyieres parentadas que non son de beneycion, quien las fodir aforcia e sin su grado, o la metier so si por fodella, onde defornada es ella e sus parientes... (Ledesma, pág. 249)

Mas aquel que manifiesto fuere del ençendimjento, enpero dixiere que por ocasión avino \& non de su grado, jure con doze vezinos \& sea creydo (Úbeda, pág. 267)

E sy dixiere que a su grado non la mato, jure que diz verdat \& peche la meytad de la calonna \& el sennor rretengala para sy (Úbeda, pág. 379)

26 «(De avuelta $)$ adv. m. ant.... «Mio Çid, quando los vió fuera, cogiós como de arrancada; / cojás Salón ayuso, con los sos abuelta anda» (P. del Cid, ed. Menéndez Pidal, 588). "Quando çerca de tierra fueron los caballeros, dieron entre los moros, dando golpes çerteros... / A vuelta destos ambos, que del çielo vinieron, / aforzaron christianos, al ferir se metieron» (Berceo, San Mill., 441). A vueltas, adv. m. ant. Avuelta...» (Real Academia de la Lengua, DRAE, 1933).

${ }^{27}$ Real Academia de la Lengua, $\operatorname{DRAE}$ (22 ed.), t. I, 2001, pág. 1150. 


\subsection{Por cabo, de cabo}

Tanto la locución adverbial por cabo (una vez) como su variante, por su cabo (tres veces), se encuentran en el Fuero de Ledesma y la última también en el de Salamanca. Los fueros de Úbeda (doce veces) y de Alcalá recogen la locución de cabo.

En cuanto a por cabo, el DRAE la presenta con o sin artículo, por (el) $c a b o$, y explica que se trata de una locución antigua con el significado de 'extremadamente' 28 , aunque en los ejemplos hallados en los fueros parece presentar otro significado: 'por su cabeza', 'por su parte'. En cambio, de cabo tiene claramente un significado diferente y se encuentra en numerosas ocasiones junto al verbo demandar ${ }^{29}$. Resulta llamativo, siguiendo los ejemplos del CORDE, que con el paso del tiempo aparezca la expresión de cabo a cabo (que no lo passe de cabo a cabo; y lleue de cabo a cabo; y si cuentan su edad de cabo a cabo; leerlo de cabo a cabo), junto con la temporal de cabo de año (que se recoge hasta la actualidad), hasta llegar a la actual de cabo a rabo, desde finales del siglo XVIII (encajad de cabo a rabo; sabe la misa de cabo a rabo, etc.).

Esta locución se encuentra desde el año 931, en un texto en latín, hasta al menos 1992, ya que se presenta en el $D R A E$ como una locución adverbial antigua con el significado de 'nuevamente'. Los diferentes Diccionarios de la Real Academia la recogen hasta el de 1950, en el que no aparece, pero se encuentra otra vez en el de 1970 y a partir de este Diccionario se halla en unos sí $\mathrm{y}$ en otros no, casi alternativamente ${ }^{30}$.

Del significado, el DCECH indica que «la locución antigua de cabo 'otra vez', 'de nuevo' [...] se explica por los trabajos que deben hacerse empezando

28 Ibíd., pág. 379.

29 De la misma manera se halla en muchos de los ejemplos del CORDE, aunque también destaca en otros contextos, como: e tu tornarás so coraçon de cabo; mando de cabo que tod aquel...; prendalo el seguidor et de cabo pare el engenio; el pellegero cosgala de cabo sin preçio; con la osadía farié por aventura de cabo recadía; tornaron y de cabo; cometiólo de cabo con figuras...; podra responder de cabo el fiador; deuenlo sacar y poner de cabo sobre...; la meten de cabo en el fuego; peyndrar de cabo; uender de cabo; pagar toda la deuda de cabo; de cabo deue ser citado; si de cabo fiziere alguna...; de cabo deue pagar...; non sea seynnalada de cabo; plázenos de dezir de cabo las cosas...; que en nenguna manera sean de cabo demandadas; partir de cabo; e si pora auentura de cabo quiera enbrauir; et dixo de cabo, etc.

30 Aparece en todos los Diccionarios de la RAE hasta el de 1950, en el que no se encuentra por primera vez, como tampoco en los Diccionarios Académicos de 1956, 1983, 1989, pero sí reaparece en los Diccionarios de 1970, 1984 y 1992. En todos los casos en los que se encuentra recogida se explica como un «m. adv. ant.» con el significado de 'nuevamente'. Ya desde el Diccionario de Autoridades se recoge también la locución de cabo a cabo que se explica como «phrase que vale lo mismo que de un extremo á otro, del principio al fin» (pág. 29). Es en el $D R A E$ de 1869 cuando se recoge por primera vez, junto a de cabo, y de cabo a cabo, la locución de cabo a rabo, con el mismo significado que la anterior, es decir, 'del principio al fin'. Así se sigue presentando en los Diccionarios de 1884, 1889, 1914, 1936 y 1939. (Real Academia Española, Diccionarios Académicos, en http://www.rae.es/). 
por la extremidad de un objeto: en ellos 'empezar de nuevo' es empezar de cabo o por el cabo».

Sin duda, la evolución de esta locución ha debido ser la siguiente: de la originaria de cabo, se llegó a de cabo a cabo, con otro significado: 'de principio a fin', y ésta acabó convirtiéndose en de cabo a rabo, tal vez por entender que si cabo significaba 'principio', el vocablo rabo expresa con claridad 'el fin' al tratarse de 'la extremidad o parte final de un animal'. A ello debió contribuir la semejanza fonética cabo / rabo, y, de ahí, que se produjera el cambio. Como señalan Contreras y Súñer es frecuente en las locuciones el uso de aliteraciones, rimas o fórmulas apofónicas ${ }^{31}$.

Se observa aquí la desmotivación de cabo < CAPUT 'cabeza', a diferencia de la locución por (su) cabo, y la adquisición de nuevos significados secundarios por un proceso metafórico como 'principio', 'fin', 'cabeza'. Ello permite comprobar la importancia de la metáfora y de la metonimia en el cambio semántico desde el punto de vista de la semántica cognitiva ${ }^{32}$. Podría aplicarse a las locuciones adverbiales la consideración de Dworkin, a propósito de la adquisición por una palabra de un nuevo significado, de que, en realidad, son los hablantes quienes «comienzan a emplear los vocablos de una manera novedosa e innovadora ${ }^{33}$. Los ejemplos del corpus son éstos:

Ningun omne non prinde bestia de aldeano, si non por cabo o por cosa que pertenez aconceyo (Ledesma, pág. 250)

Et se otra manera prindar por su cabo, pierda el andaduria e quanto seruicio fizier (Ledesma, pág. 252)

E sy aquella muger de cabo consintiere a su rrabiador, sea enemjga con él (Úbeda, pág. 300)

el primer día que juzgaren es día sean soltas e el júdez novo demándelos de cabo (Alcalá, pág. 495)

\subsection{A buena fe, con buena fe}

La locución adverbial a buena fe y su variante con buena fe se encuentran en el Fuero de Salamanca, formando parte de una expresión compleja que parece tratarse de una fórmula: con buena fe y sin mal engaño. No es una locución frecuente en los fueros, de hecho sólo aparece en uno de los estudiados y únicamente en dos ocasiones. Esto contrasta con su gran frecuencia de aparición en la documentación notarial, en la que se presenta con variaciones en

\footnotetext{
31 Joan M. Contreras, y Avel-lina Súñer, «Los procesos de lexicalización», art. cit., pág. 89.

${ }^{32}$ Luis Antonio Santos y Rosa Espinosa, Manual de Semántica Histórica, Madrid, Síntesis, 1996.

${ }^{33}$ Steven N. Dworkin, «La naturaleza del cambio léxico», Actas del VI Congreso Internacional de Historia de la Lengua Española, I, Madrid, Arco-Libros, 2006, pág. 67.
} 
cuanto a la preposición que la introduce y tanto en latín como en romance. Éstos son algunos de los ejemplos:

Plogo anuestro senor el rey don Ffernando que todo el pueblo de Salamanca todo sea uno con bona fe e sin mal engano (Salamanca, pág. 168)

Mas seamos todos unos abona fe, sin todo mal engano, ahonor de Dios e de nuestro senor el rey don Ffernando e de todo el conceyo de Salamanca (Salamanca, pág. 169)

\subsection{Por ventura, en buena ventura}

En cuanto a la primera locución, por ventura, que puede leerse con bastante frecuencia en los documentos notariales de diferentes scriptae hispánicas, se encuentra en los fueros de Zamora, de Alcalá y de Úbeda. En éste último destaca su constante presencia ya que aparece al menos ciento cuarenta y seis veces, en la mayoría de los casos formando parte de una estructura con apariencia de fórmula: E sy por auentura, con algunas alternancias: mas por auentura, o por auentura, etc. En el Fuero de Alcalá se halla junto a por ventura (dos veces) también en buena ventura (una vez):

e al que no'l semejare baya en bona ventura ó que's quisiere. Si por abentura el señor detardare de poner aportellados, los jurados ayan acomendada la villa de tenerla a derecho (Alcalá, pág. 495)

E se por auentura salir, matenlo por que non faga danno (Zamora, pág. 61) E el que por auentura conplir non pudiere, salga enemigo por anno (Úbeda, págs. 318-319)

\subsection{Por siempre, por siempre jamás}

La locución adverbial por siempre, con el significado de 'perpetuamente', aparece en el Fuero de Alcalá, con la variación per siempre, en cuatro ocasiones. Curiosamente, en todos los casos en relación con otros compuestos, de significado similar, y también con apariencia de locuciones adverbiales. Se trata de las expresiones (por) todo el año y por en sos días / después de sos días. Asimismo, se encuentra en los fueros de Ledesma y de Úbeda, en el que, junto a por siempre (en cuarenta y una ocasiones), se encuentra igualmente, aunque tan solo una vez, por siempre jamás. Estas locuciones se muestran también en los documentos notariales, si bien con menos frecuencia dada su evidente preferencia por las fórmulas con expresiones temporales. En los fueros, pues, a falta de fórmulas temporales, destaca la presencia de locuciones temporales. Algunos ejemplos:

Que quieren que sea devedada todo el año por siempre la defesa de Oruga e el sotiello, que non entren ý de todo ganado de ovejas, e de porcos, e de cabras e de todos ganados por todo el año por siempre (Alcalá, pág. 506) 
Enpero el cauallero que cauallo toujere en su casa en valia de çinquenta mencales arriba, non peche en muros njn en torres njn en otras cosas njngunas por siempre jamas (Úbeda, pág. 256)

\subsection{Para siempre, para siempre jamás}

En el Fuero de Úbeda se encuentran las locuciones adverbiales temporales para siempre, en cinco ocasiones, y sólo en una para siempre jamás ${ }^{34}$, en ejemplos como:

Mando aun a uos que todo aquel que rrayz oujere, que la aya firme $\&$ estable $\&$ que vala para siempre, assy que pueda della \& en ella fazer lo quel plogiere (Úbeda, pág. 260)

Conosçida cosa sea a todos los omnes que son en presente $\&$ son por venjr que nos, el conçejo de Ubeda, juez \& alcaldes, afirmamos por fuero para sienpre jamas que en el dia de Sant Mjguel venga vn cauallero \& vn alcalde de cada collaçion a jurar (Úbeda, pág. 403)

\subsection{A sabiendas}

Esta locución adverbial, con el significado de 'de modo cierto, con conocimiento del hecho', presenta continuidad hasta la época actual.

No se encuentra en textos notariales, tal vez por tratarse de una expresión locucional más propia de la oralidad y, como tal, se mantiene hasta la actualidad. Su ausencia en la documentación notarial estudiada quizá no sea determinante, dado que podría encontrarse en otros textos notariales de seguir con el análisis de este tipo de escritos. No obstante, sí puede afirmarse que no es tan frecuente en los documentos notariales como en los forales. La razón estriba, tal vez, en que el carácter marcadamente coloquial de ésta y otras locuciones adverbiales del corpus, las acerca a los textos forales en detrimento de los notariales. Y ello pone de manifiesto una clara diferenciación entre ambos tipos de lenguaje jurídico, el notarial, en el que la escritura se hace más patente, y el foral, en el que se impone más, si cabe, la oralidad. Se halla en los fueros de Ledesma, de Alcalá, en cinco ocasiones, y de Úbeda:

Omne que a mal de fuera a sabiendas que toda sua uizindade sabe quelo a, non peche; si lo non crieren, firmelo con III uizinos e non peche (Ledesma, pág. 274)

De la muger que a sabiendas abortare. Otrosy, muger que a sabiendas abortare, sea quemada, si manjfiesta fuere (Úbeda, pág. 303)

${ }^{34}$ Consideramos que la locución para siempre jamás está formada por dos adverbios, aunque en alguna ocasión se haya dudado de la plena lexicalización de jamás en el s. XIII. 


\subsection{En doble}

Esta locución adverbial aparece en los fueros de Ledesma y de Úbeda, en este último predomina la variación en doblo, tres veces, frente a en doble, una sola vez:

E si sobrellos lo firieren o messaren o enpellaren, peche la calonnia endoble (Ledesma, pág. 278)

Sy el querelloso sobre pennos en doblo firmare, lugo dé el juez los pennos al que firmare (Úbeda, pág. 342)

\subsection{De manifiesto}

Se encuentra únicamente en el Fuero de Ledesma. Es más frecuente, por tanto, en los documentos notariales que en los textos forales. En éstos últimos parece que no hay intención de utilizar, al menos con frecuencia, toda aquella locución adverbial que presente aspecto de fórmula, como ocurre en este caso:

Et se algun omne ychar penos aiudio aganancia, tengalos el iudio de manifiesto (Ledesma, pág. 286).

\subsection{A mano}

No se trata tampoco de una locución frecuente; aparece solo en el Fuero de Ledesma:

Alcalldes que bestia touieren en corral, se la dier que lle la tornen amano, oprindes, e non llos tornaren, sea la prinda amortiguada (Ledesma, pág. 250)

\subsection{En alto, en ancho, en luengo, en gordo y de longuez}

La locución adverbial en alto se encuentra en el Fuero de Alcalá en una ocasión, in alto, y en el de Ledesma. En el Fuero de Úbeda aparecen las locuciones en luengo y de longuez, con el mismo significado, esto es, 'de largo', y también las locuciones en ancho y en gordo, ambas con un significado semejante, es decir, 'de ancho':

E se el senor payar non ouier, fagalo el iuguero, payar de III cabriadas, de un stado de omne mediano e mesurado en alto (Ledesma, pág. 274)

Los maestros de las tejas \& de los ladriellos fagan las tejas de dos palmos en luengo \& en la goda palmo \& medio \& en gordo aya quanto el artejo del pulgar (Úbeda, pág. 398)

E la forma de los adriellos aya en ancho vn palmo grant \& en luengo palmo \& medio \& en alto dos dedos (Úbeda, pág. 399)

Marçales dezimos sy quier truchas sy quier barujellos que ouieren de longuez vn cobdo sin cabeça \& sin cola, el punno çerrado (Úbeda, pág. 401) 


\subsection{De pie, por el pie}

Se trata de dos locuciones adverbiales de significado similar a la locución actual a pie. Se encuentran en el Fuero de Úbeda, en el último caso con el significado de 'el ballestero de a pie'. Estas locuciones adverbiales, al igual que $a$ mano, en alto, en ancho, en luengo, en gordo, de longuez y otras, se han encontrado únicamente en los fueros y no en los escritos notariales, tal vez por tratarse de expresiones más próximas a la lengua oral. De nuevo, se aprecia la diferencia entre estos dos tipos de textos jurídicos, es decir, las locuciones adverbiales de los documentos notariales parecen aportar una mayor carga de solemnidad, están más próximas a las fórmulas que las locuciones adverbiales de los fueros, donde se hace patente la oralidad y, por lo tanto, se evitan aquellas expresiones que resultan más formularias. Aun así, ambos tipos de texto comparten muchas locuciones adverbiales, algunas de las cuales trascienden de este lenguaje técnico jurídico, y se utilizan de forma general en otros contextos. Ejemplos:

E quando fueren venidos a la heredat, el querelloso destermjnela toda en derredor, andandola por el pie (Úbeda, pág. 261)

Luego en aquel lugar diga sy quiere lidiar de pie o de cauallo (Úbeda, pág. 343)

El ballestero de pie que troxiere ballesta con $\mathrm{C}$ saetas prende media parte por ella (Úbeda, pág. 364)

\subsection{A vez, en su vez}

En los fueros de Salamanca y de Úbeda se halla una variante de la locución actual a la vez, ya que se presenta con la forma en su vez, mientras que en el Fuero de Alcalá se recoge la variante sin determinante a vez, que se encuentra desde 1234 hasta al menos 1958 en el CORDE y siempre en escritos en romance. A la vez es más tardía, se documenta en el CORDE a partir de finales del $\mathrm{XV}$ y se generaliza desde 1506. No se han encontrado otras variantes. Algunos ejemplos son éstos:

Todo omne de Salamanca o de su termino que rancura ouier de su uezino, de morte o de desondra o de ferida, desafiel con III uezinos que desafien en su uez (Salamanca, pág. 86)

... otrossí, si los andadores a bez non vinieren tener la porta so mes al biernes a los fiadores, peche I mencal a los fiadores si non fore ido en mandadería (Alcalá, pág. 486)

\subsection{A su par}

En el Fuero de Úbeda se muestra la locución adverbial a su par, variante de la locución actual a la par, en catorce ocasiones, en ejemplos como éste: 
Mas aquel que negare \& nol pudieren prouar jure con doze vezinos o rresponda a su par (Úbeda, pág. 297)

\subsection{A tuerto}

Se trata de una locución propia también de la documentación notarial. Parece utilizase con el mismo significado que a tuertas, esto es, 'al revés de cómo debe hacerse'. En esta locución se ha producido ya la desmotivación total y en la lengua jurídica presenta una primera fijación formal, que irá evolucionando una vez haya transcendido el ámbito jurídico hasta llegar a la locución coordinada a tuerto o a derecho, con algunas variantes ${ }^{35}$. Esta locución, común a varios romances, alterna con una variante en femenino plural a tuertas, ambas recogidas en el Diccionario de Autoridades, la primera con el significado de 'Sin confideración, ni reflexion jufta o injuftamente' y la segunda con el de 'al revés de cómo $\int$ e debe hacer u obliquamente ${ }^{36}$. Éste último significado, documentando más tardíamente según A. Ricós, parece ser el que presentan los ejemplos del corpus. De ahí se llegó a un significado más general: 'sin razón, injustamente, sin derecho', si bien es una locución poco frecuente hoy en día.

Se halla en los fueros de Úbeda (seis veces) y de Alcalá (dos veces):

E sy por auentura el prendado dixiere que a tuerto es prendado, firme el sennor los pennos tenjendo en la mano (Úbeda, pág. 265)

A tuerto $\cdot \mathrm{m}$ desafia ca sabe quién mató so pariente (Alcalá, pág. 466)

\subsection{A medias}

Igualmente en el Fuero de Úbeda aparece esta locución adverbial:

Del que bestia diere a medias. Qualquier que bestia diere $a$ medias \& la perdiere peche la meytad \& non mas (Úbeda, pág. 312)

\subsection{A desdén}

En dos ocasiones se presenta esta locución adverbial en el Fuero de Úbeda:

Qualquier que a otro a desden enpellare peche dos morauedis (Úbeda, pág. 305)

35 Así lo ha señalado Amparo Ricós Vidal, «De locuciones coordinadas a sintagmas complejos. A propósito de a diestro y siniestro, a tuerto y a derecho, a tontas y a locas», en Actas del XXXVII Simposio de la Sociedad Española de Lingüística (Pamplona, diciembre de 2007), Universidad de Navarra, 2008, págs. 707-717. http://www.unav.es/linguis/simposiosel/Act.

${ }^{36}$ Real Academia Española, Diccionario de Autoridades, 1739, en http://corpus.rae.es. 


\subsection{Con verdad, a verdad}

En el Fuero de Alcalá aparece en una ocasión la locución adverbial con verdad, mientras que en el de Úbeda se recoge la variante a verdat, en dos ocasiones, ambas con el mismo significado de la locución de verdad, es decir, 'a la verdad. De veras'. Parece, por tanto, que la locución originaria pudo ser ésta, a verdad, con variación en cuanto a la preposición, como ocurre en otras muchas locuciones, tanto en los fueros, en casos como por/alen fuero, por/a/con fuerza, en/por guisa, a/de vuelta, por/a bien, etc., como en los documentos notariales, en los que destacan alternancias como la que se aprecia entre a/de/en buena $f^{37}$, etc. No se trata tampoco de una locución propia de la documentación notarial, tal vez por estar más próxima de nuevo a la oralidad. Ejemplos:

...e si alguno de los conombrados no·l quisiere salvar jure-l con II bezinos que $a$ verdad lo aduze e sálvelo (Alcalá, pág. 478)

E sy con verdat fuere que las firmas non fueren en el termjno, qual ora el querelloso las pudiere auer, ponga de cabo plazo con su contendor (Úbeda, pág. 354)

\subsection{En orden}

En el Fuero de Úbeda se encuentra esta locución adverbial en dos casos:

Del que en orden entrare. E qualquier de uso que en orden entrare lieue el quinto consigo del mueble \& non mas, \& lo al con toda su rrayz finque a los herederos (Ưbeda, pág. 287).

\subsection{De dentro, de fuera}

En los fueros de Ledesma, de Úbeda y de Alcalá destacan estas locuciones. En el último siempre con la variante de foras en cinco ocasiones, y junto a la locución preposicional de fuera de, mucho más frecuente en el texto. Ejemplos:

Todo omne qui de foras viniere ad Alcalá o a so término a morar non peche... (Alcalá, pág. 492)

Mas enpero, sy el rreptado fuere ljuençioso en aquella ora que fuere rreptado, y lugo demuestre la ljuençia, sy de fuera la oujere. Mas sy de dentro oujere la liuençia, o en lugar que verguença aya de la demostrar, jure que por aquella ljuençia delexa de lidiar,... (Úbeda, pág. 343)

37 Adela García Valle, «Las locuciones adverbiales en la documentación notarial medieval», art. cit. 


\subsection{De allende}

La locución adverbial de allende se halla en los fueros de Alcalá y de Salamanca. En el primero, junto a dallent serra se encuentra daquén serra, que no puede considerarse como locución por no presentar continuidad alguna:

Ajunte los ermanos daquén serra e por los dallent serra dé fiador e responda (Alcalá, pág. 473)

E el coto delos lidiadores sea dela riba dalende asta o cae el brazo eno rio, edel oriela del rio por todo el arnal. E si al rio entrar o ela riba del brazo passar, sea arrancado, sin non pudier que el cauallo lo passo el rio alende sin grado (Salamanca, pág. 113)

\subsection{En derredor}

En seis ocasiones aparece esta locución adverbial en el Fuero de Úbeda:

Toda fuente de conçejo aya en espaçio en derredor tres estados (Úbeda, pág. 277)

\subsection{En su vida}

Esta locución adverbial se encuentra en el Fuero de Zamora:

... ellos fillos no le podan passar aelas en sua uida (Zamora, pág. 34)

\subsection{Por corazón}

Es variante de la locución actual de corazón y se encuentra en el Fuero de Úbeda. Recurrir a una metonimia para conseguir el valor abstracto que da lugar a una locución es un procedimiento frecuente de creación de locuciones. La pérdida de motivación llega a crear un sentido figurado, como en este caso:

... \& con aquellas cosas que por coraçon amades (Úbeda, pág. 354)

\subsection{De пиеvo}

En el Fuero de Úbeda destaca esta locución adverbial en ejemplos como éste:

E avn aquel moljno faze de nuevo, cate que non enpesca al moljno que ante fue fecho, de qual parte quier, sy quier de suso, sy quier dyuso, sy quier de diestro sy quier de siniestro (Úbeda, pág. 280) 


\subsection{De diestro, de siniestro}

Estas dos locuciones adverbiales se muestran en dos ocasiones, y en el mismo fuero, formando parte de un sintagma complejo, con un claro significado locativo, el de 'por todas partes'. A. Ricós ya observó, a propósito de la locución a diestro y a siniestro que en los textos más antiguos aparecían los dos sintagmas de manera independiente, introducidos por las preposiciones AD e IN para indicar valores locales como los de 'movimiento' o 'desplazamiento en dirección a', al menos hasta finales del XIII ${ }^{38}$. Pues bien, dado que en el corpus la preposición que acompaña a estas locuciones es de, añadimos esta preposición a las que pueden introducir dichas locuciones en los textos antiguos. Como sigue diciendo A. Ricós, parece que ambas locuciones tienden a unirse para expresar un significado figurado. Así, partiendo del valor local 'a la derecha' y 'a la izquierda', se llega al significado de 'por todas partes', que es el que parece desprenderse del sintagma complejo de los ejemplos del corpus. En cualquier caso, estamos ante el antecedente de la locución a diestro y a siniestro con el significado local adquirido a partir del siglo XIV, y sin llegar aún a la desmotivación que se aprecia en el sentido figurado, mantenido hasta hoy en día de 'sin orden ni reflexión', desde principios del XVI o con anterioridad. Ambas locuciones se hallan en el Fuero de Úbeda y, al presentarse encadenas, parecen constituir una fórmula:

E avn aquel moljno faze de nuevo, cate que non enpesca al moljno que ante fue fecho, de qual parte quier, sy quier de suso, sy quier dyuso, sy quier de diestro sy quier de siniestro (Úbeda, pág. 280)

\subsection{De sol a sol}

La locución adverbial de sol a sol se encuentra en una ocasión en el Fuero de Alcalá. Se presenta con el significado de 'desde que sale el sol hasta que se pone'. En el CORDE se recoge de sol a sol puesto que podría ser la locución originaria de la que procede de sol a sol, o tratarse simplemente de una variante. Coincide la lengua foral con la notarial en el uso de esta locución temporal que llega hasta hoy en día. Ejemplo:

Peños que foren soltos per voca de alcaldes, de sol a sol los pida (Alcalá, pág. 505)

\footnotetext{
38 Amparo Ricós Vidal, «De locuciones coordinadas a sintagmas complejos», art. cit.
} 


\subsection{A sueltas}

La expresión locucional a soltas se muestra dos veces en el Fuero de Alcalá. Parece significar 'libremente', al igual que los ejemplos del $C O R D E^{39}$, de 1275, pertenecientes a Alfonso X. Esta locución presenta también cierta variación, ya que, junto a la forma a soltas, que podría considerarse un arcaísmo gráfico, se recoge asimismo en el CORDE la variante a suelta ${ }^{40}$, con el mismo significado, en las mismas fechas y en la obra alfonsí, donde se alterna, pues, en el uso de las dos variantes:

Todo omne qui oviere lavor de bueis por pan e oviere cavallo o mula, o mulo o bestia de siella, a soltas coma en era <...> al vivo I bestia, e si mais (36v) quisiere tomar dé so quinto al juvero. La bestia que las mieses trasiere a soltas coma en era e en era fasta pan cogido de era (Alcalá, pág. 496)

\subsection{A osadas ${ }^{41}$}

Se encuentra en el Fuero de Alcalá, en tres ocasiones, con el significado de 'sin miedo, con resolución, con seguridad', como puede verse en este ejemplo:

Todo omne de la villa qui aldea oviere e bestia oviere de siella, cuando fuere al aldea $a$ osadas den su bestia a pacer en la defesa sin caloña ninguna, e qui ja acortare peche $\mathrm{V}$ moravidís; e la bestia del omne de la villa, trayéndola por cabestro a osadas pasca en los cotos (Alcalá, pág. 508)

\subsection{De allí adelante, de este día adelante}

En el Fuero de Alcalá destaca la locución temporal de allí adelante, propia también de los documentos notariales, al igual que la variante de este día ade-

\footnotetext{
${ }^{39}$ En el CORDE: e mandaron por pueblo que andidiesse a sueltas por ó quisiesse...; segavan todas sus miesses a sueltas e cogién...; e andando a sueltas...; obrauan estonces $a$ sueltas... (1275, Alfonso X).

${ }^{40}$ También en el CORDE: e visquiessen e andidiessen aquel seteno año a suelta por ó quisiessen; mas que assí se andavan todos $a$ suelta por las tierras e por los montes... (1275, Alfonso $\mathrm{X}$ ).

${ }^{41}$ El proceso de fijación, gramaticalización y desmotivación total de esta locución, común a todas las lenguas romances y documentada en español desde 1140 hasta 1982, ha sido estudiado detenidamente por A. Ricós Vidal («Locuciones adverbiales con preposición $a$ y adjetivo en el español y el portugués del siglo XVI. Estudio histórico», en C. Company Comany y J. G. Moreno de Alba, Actas del VII Congreso Internacional de Historia de la lengua española, op. cit., vol. I, págs. 1035-1054). Explica que pasó de significar 'osadamente, con atrevimiento' al significado de 'sin miedo, con seguridad' con un cierto valor intensificador que facilitó su conversión en un adverbio de modalidad de la aserción hasta llegar a ser «un conector coloquial con la función discursiva de retomar el turno de palabra reafirmando lo dicho anteriormente por otro interlocutor». Su presencia en textos coloquiales la marcó diastráticamente y esto pudo provocar su desaparición.
} 
lante que en este fuero se presenta como d'es día adelant (una vez), junto con las expresiones temporales de (entrada de) marzo adelant y de sant Martín adelant(e). Ejemplos:

e si non pudiere firmar salve's con VI e él el seteno, e d'alli adelant sea encortado [...] D'esto hata tercer día non faga nemiga; e si dixiere que luego's quiere ir d'este dia adelant o'l testiguaren en casa peche XXX moravidís (Alcalá, pág. 481)

\section{ESTUDIO LINGÜÍSTICO DE LAS LOCUCIONES ADVERBIALES}

Una vez presentadas las locuciones adverbiales forales, sigue a continuación el análisis lingüístico de éstas por las numerosas consideraciones de interés que destacan.

\subsection{Estudio morfológico}

Se ratifica la observación general de que se trata sobre todo de sintagmas prepositivos (Pavón Lucero ${ }^{42}$ Corpas $^{43}$, García-Page ${ }^{44}$ ). A excepción de las locuciones introducidas por dende y ende, todas las otras locuciones son sintagmas preposicionales:

\subsubsection{Locuciones formadas por preposición + elemento nominal o adjetival ${ }^{45}$}

Este grupo se constituye en el más numeroso del corpus:

Prep. + Sustantivo: en paz, por/alen fuero, por/a/con fuerza, por/a/con derecho, en guisa, a/de vuelta, sin grado, por cabo, de cabo, por ventura, de manifiesto, a mano, de longuez, de pie, a vez, a desdén, con/a verdad, en orden, en derredor y por corazón.

Preposición + SN: por suleste fuero, por la/su fuerza, en/por tal guisa, sin su grado, dela su grado, por su cabo, a/con buena fe, en buena ventura, por el pie, en su vez, a su par, en su vida.

Prep. + Adjetivo: en doble, en alto, en ancho, en luengo, en gordo, a tuerto, de nuevo, de diestro, de siniestro.

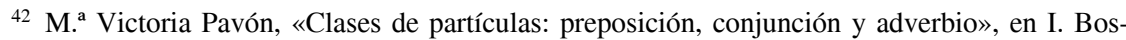
que y V. Demonte, eds., Gramática descriptiva de la lengua española, Madrid, Espasa- Calpe, 2000, pág. 614.

${ }^{43}$ Gloria Corpas, Manual de fraseología del español, op. cit., pág. 99.

${ }^{44}$ Mario García-Page, 1991, «Locuciones adverbiales con palabras 'idiomáticas'», Revista española de lingüística, 21, 2, 1991, pág. 244.

${ }^{45}$ M. ${ }^{\text {a }}$ Victoria Pavón, «Clases de partículas: preposición, conjunción y adverbio», art. cit., págs. 615-616. 
Prep. + Adj., o Adj. participial, en femenino plural: a osadas, a medias, a sueltas.

Prep. + palabra idiomática: a sabiendas.

4.1.2. Locuciones formadas por más de una preposición

Prep. + Prep. + Adverbio: de a yuso, en a yuso.

4.1.3. Locuciones formadas por adverbios precedidos o no de preposición

Adverbio + Adverbio: dende arriba, dende adelante.

Adv. + Prep. + (Prep.) + Adv.: dende a yuso, ende a yuso, ende en a yuso.

Prep. + Adverbio: por ende, por onde, a yuso, de yuso, a suso, de suso, por bien, a bien, por siempre, para siempre, de dentro, de fuera, de allende, en arriba, a arriba.

Prep. + Adv. + Adv.: de allí adelante, por siempre jamás, para siempre jamás.

Sintagma Preposicional + Adverbio: de este día adelante.

\subsection{Estudio sintáctico-funcional}

4.2.1. Funciones desempeñadas por las locuciones adverbiales

Principalmente se trata de la función terciaria, al igual que los adverbios, modificando a un verbo en la mayoría de las ocasiones (rresponda a su par, que desafien en su uez; del que bestia diere a medias...); por ello actúan como complemento circunstancial, y, a nivel textual, pueden funcionar como modalizadores (si non los tornare aquel dia, de cabo peche $\mathrm{V}$ sueldos...; E sy por auentura salir, matenlo...; Deinde arriba, los omnes que oviere opus el pastor...), anafóricos (como es dicho de suso), o conectores (E si por ende algun omne le demostrar mal querencia...). Señalan «circunstancias no inherentes al proceso expresado por el verbo de la oración de la cual forman parte» ${ }^{46}, \mathrm{y}$, además, algunas de estas locuciones mantienen cierta independencia funcional ya que, de suprimirse, el contenido apenas se ve alterado ${ }^{47}$. Así pues, como puede constatarse en el corpus, la mayor parte de las locuciones adverbiales, aun siendo tales por equivaler desde el punto de vista funcional a los adverbios, proceden, en realidad, de la lexicalización de otras categorías (Contreras y Súñer ${ }^{48}$ );

\footnotetext{
${ }^{46}$ Gloria Corpas, Manual de fraseología del español, op. cit., pág. 100.

${ }^{47}$ Leonor Ruiz Gurillo, «Relaciones categoriales de las locuciones adverbiales», Contextos, XV/29-30, 1997, pág. 28.

48 Joan M. Contreras, y Avel·lina Súñer, «Los procesos de lexicalización», art. cit., pág. 80.
} 
es el caso de las expresiones locucionales de grado, por fuerza, en doble, por corazón, a tuerto, etc.

4.2.2. Proceso de fijación de las preposiciones en las locuciones adverbiales

Se observa, en primer lugar, al igual que en la documentación notarial analizada, la alternancia entre varias preposiciones para una misma locución: a/con buena fe, por/alen fuero, en/por guisa, a/de vuelta, dela (su) grado, por/de cabo, con/a verdad, a/de yuso, a/de suso, por/a bien, por/para siempre, por/ para siempre jamás, en/a arriba, etc. Las preposiciones que introducen las locuciones adverbiales son éstas:

- la preposición a encabeza sobre todo locuciones modales y algunas espaciales: a buena fe, a la par, a vuelta, a mano, a pie, a vez, a desdén, a grado, a verdad, a yuso, a suso, a arriba, a tuerto, a sabiendas, a medias, a osadas, a sueltas...

- la preposición de introduce locuciones modales, espaciales y temporales: de vuelta, de manifiesto, de longuez, de pie, de grado, de cabo, de yuso, de suso, de dentro, de fuera, de allende, de nuevo, de diestro, de siniestro, de sol a sol, de allí adelante...

- la preposición en introduce principalmente locuciones modales y una de cantidad: en buena ventura, en su vez, en fuero, en su vida, en paz, en guisa, en orden, en doble, en alto, en ancho, en luengo, en gordo, en arriba...

- la preposición por se reserva para las locuciones modales, ya que su presencia en algunas temporales y locales resulta mucho más restringida: por el pie, por fuero, por (la, su) fuerza, por derecho, por guisa, por cabo, por ventura, por bien, por siempre, por ende, por onde, por siempre jamás...

- la preposición para sólo introduce locuciones temporales: para siempre (jamás).

- la preposición con se halla en locuciones modales: con buena fe, con verdad...

- la preposición sin aparece únicamente en una locución modal: sin grado.

\subsubsection{Moldes sintácticos para la formación de locuciones adverbiales forales}

Uno de estos moldes, especialmente en las de modo, es el del sintagma formado por prep. + adj. en masculino: en alto, en ancho, en luengo, en gordo, a tuerto, de diestro, de siniestro, etc. Aquí coincide también con la lengua notarial, y ello lleva a pensar que pueda tratarse de una característica propia del 
lenguaje jurídico en general. Bien es verdad que empieza a apreciarse, tal vez únicamente en el registro foral, el sintagma siguiente: $a+$ adj. participial o, en su lugar, una palabra idiomática, siempre con la terminación en -as: a sueltas, a medias, a osadas, a sabiendas... ${ }^{49}$.

Además, la presencia de locuciones modales como a tuerto, en alto, en ancho... contradice la afirmación de Martínez López de que una estructura de este tipo jamás presenta el adjetivo en masculino ${ }^{50}$. El análisis de las locuciones adverbiales aquí presentadas demuestra que, en la etapa medieval, se utilizaban tanto las locuciones con el adjetivo en masculino, las más abundantes, como las que presentaban el elemento nominal en femenino pl.: a sabiendas, a sueltas, a medias, a osadas, menos numerosas.

\subsection{Estudio semántico}

Las locuciones halladas expresan distintos valores referenciales. Coinciden, en concreto, con los ya señalados por $\operatorname{Corpas}^{51} \mathrm{y}$, más recientemente, por Contreras $^{52}$; esto es, los de modo, localización en el tiempo y localización en el espacio principalmente, a los que se añaden, como un subtipo del valor modal, los de medida y cantidad (a veces con referencia al dinero). Ya para GarcíaPage, el grupo más numeroso lo constituían las locuciones modales ${ }^{53}$. En los fueros analizados también son las más abundantes.

Las locuciones adverbiales modales son, pues, las siguientes: en paz, por/a/ en fuero, por/a/con fuerza, por/a/con derecho, en/por guisa, a/de vuelta, sin grado, dela grado, por cabo, de cabo, con/a buena fe, por ventura, en buena

${ }^{49}$ El sintagma formado por la preposición $a$ seguido de un elemento nominal ha sido estudiado tanto desde una perspectiva sincrónica (Juan Antonio Martínez, «La adverbialización modal con la preposición a», Lingüística Española Actual, XXI/1, 1999, págs. 67-97. Joan M. Contreras, «Análisis de algunas construcciones fronterizas entre la composición y la sintaxis», en Pérez Gaztelu, Zabala y Gràcia, eds., Las fronteras de la composición en lenguas románicas y en vasco, op. cit., pág. 280) como diacrónica (Amparo Ricós Vidal, «Locuciones adverbiales con preposición a...», art. cit.). Esta última perspectiva ha permitido considerarlo un procedimiento muy productivo en la «formación de locuciones adverbiales con valor modal en español, en portugués y en catalán». A. Ricós también considera que, más común que la estructura formada por la preposición $a$ seguida de un sustantivo es la formada por la preposición $a$ seguida de un adjetivo o adjetivo participial, generalmente en femenino plural, precedido o no de artículo.

50 Este autor opina que estas estructuras presentan el adjetivo únicamente en femenino y ello por razones históricas «pues se sabe que tales adverbios proceden del grupo concordado Adj. (fem.) + MENTE (< fem. mens, mentis), en donde el sustantivo impone su género y obliga al adjetivo a concordar con él» (Juan Antonio Martínez, Ibíd., págs. 79-80).

51 Gloria Corpas, Manual de fraseología del español, op. cit., pág. 100.

52 Joan M. Contreras, «Análisis de algunas construcciones fronterizas...», art. cit., págs. 268269.

53 Mario García-Page, «Locuciones adverbiales con palabras 'idiomáticas'», art. cit., pág. 244. 
ventura, de manifiesto, a mano, de pie, por el pie, a/en vez, a desdén, con/a verdad, en orden, por corazón, a su par, en su vida, en doble, en alto, a tuerto, de nuevo, de diestro, de siniestro, a medias, a sueltas, a sabiendas, a osadas, porla bien, por ende y por onde.

Expresan cantidad o medida las locuciones: en arriba, dende arriba, que también se utiliza para significar lugar, dende a yuso, en a yuso, a suso, en alto, en ancho, en gordo, en luengo y de longuez.

Son temporales: por/para siempre (jamás), de allí adelante y dende adelante.

Como locuciones espaciales destacan a arriba, a yuso, que asimismo puede expresar cantidad, de yuso, ende a yuso, ende en a yuso, de a yuso, de suso, de dentro, de fuera, de allende y en derredor.

\section{CONSIDERACIONES GENERALES}

El análisis llevado a cabo permite establecer una serie de consideraciones generales acerca de las locuciones adverbiales en los fueros. Son las siguientes:

La primera consideración reside en que las locuciones adverbiales modales son las más abundantes en los textos forales. Esto puede hacerse extensivo al lenguaje jurídico en general, puesto que tanto en la documentación notarial como en los fueros dominan las locuciones con este valor. La situación es distinta por lo que respecta a las locuciones adverbiales temporales, ya que se puede afirmar que existe una diferenciación en el uso que se hace de ellas en estos dos tipos textuales. Esta diferencia estriba principalmente en la frecuencia de empleo y en la cercanía a la oralidad que parece producirse en los fueros. Mientras en los escritos notariales el porcentaje de locuciones temporales no es muy alto, tal vez por la preferencia a recurrir a otras fórmulas de expresión con este valor, en los textos forales, la escasez de fórmulas temporales explica, posiblemente, que se tengan que emplear en mayor número de ocasiones locuciones adverbiales para expresar las relaciones temporales.

Como segunda consideración hay que señalar que, aunque es posible reconocer en la mayoría de las locuciones el significado originario del sintagma, esto es, el que se desprende de la suma de los valores de los elementos, destacan algunos casos en los que debido a la fijación sintáctica, al contexto lingüístico y a la frecuencia de uso, se ha producido ya una desmotivación parcial o total de la palabra que ha facilitado su gramaticalización posterior, es el caso de por ventura. Muchos de los sintagmas estereotipados del corpus parecen confirmar que «los factores que intervienen de forma total o parcial en un proceso de lexicalización son, por orden cronológico, la frecuencia de coaparición o colocación, la fijación, la especialización semántica y la idiomaticidad» ${ }^{54}$. El proce-

\footnotetext{
54 Joan M. Contreras, y Avel-lina Súñer, «Los procesos de lexicalización», art. cit., pág. 86.
} 
so de fijación se ve favorecido en algunas locuciones por la presencia de palabras idiomáticas, que permite identificar como locución la cadena de palabras en la que se encuentran, puesto que se trata de elementos lingüísticos «que, por razones diversas - históricas, principalmente-, aparecen única y exclusivamente dentro del marco de una locución» ${ }^{55}$. Serían ejemplos a sabiendas, palabra idiomática ya en la etapa medieval, o, más tarde, por ende, cuando ende deja de utilizarse como adverbio en castellano y se mantiene tan sólo en la locución ya desmotivada parcialmente. De la misma opinión es Montoro del Arco, si bien este autor añade otros rasgos que permiten caracterizar la fijación formal de las locuciones, tales como la inalterabilidad del orden de los constituyentes, la invariabilidad de alguna categoría gramatical, la inmodificabilidad del inventario de los componentes y la insustituibilidad de estos elementos ${ }^{56}$. Del estudio que precede a estas consideraciones se desprende que muchos de estos rasgos han constituido parte de la cadena de formación de un buen número de las locuciones que conforman el corpus, y ello ha permitido conocer el proceso por el que han ido adquiriendo un valor abstracto, perdiendo parte de su significado primitivo, y avanzando en el proceso de la gramaticalización. A todo esto se unen los condicionamientos internos que Martín Zorraquino ${ }^{57}$ estableció para que el proceso de gramaticalización se hiciera patente. Así, muchas de las locuciones adverbiales analizadas son, en primer lugar, propias de un tipo textual concreto, el foral (por fuero, por derecho...), por lo que algunos de sus constituyentes son «tecnicismos» o vocabulario propio del registro jurídico, $\mathrm{y}$, en segundo lugar, son objeto de relaciones interlinguiísticas evidentes con otras expresiones (con bona fe e sin mal engano, aforcia o auirto, auirto o aforcia, por forcia e uirto, uiuant in pace et in salute...). De este modo, la presencia en los fueros de las locuciones analizadas, en ocasiones encadenadas (de qual parte quier, sy quier de suso, sy quier dyuso, sy quier de diestro sy quier de siniestro), da lugar a fórmulas jurídicas características de este tipo textual. Parecen tratarse a veces de traducciones romances a partir de formularios latinos, comunes posiblemente a diferentes scriptae hispánicas ${ }^{58}$. Una vez traducidas al romance (bona fide et sine malo ingenio / con bona fe e sin mal engano...) se incorporan a los textos como estructuras repetidas y empiezan a convertirse en

55 Mario García-Page, «Locuciones adverbiales con palabras 'idiomáticas'», art. cit., pág. 235.

56 Esteban T. Montoro del Arco, Teoría fraseológica..., op. cit., pág. 41.

$57 \mathrm{M}^{\mathrm{a}}$ Antonia Martín Zorraquino, «Marcadores del discurso y diccionario: sobre el tratamiento lexicográfico de desde luego», en Echenique et alii, eds., Homenaje a Günther Haensch, Madrid, Gredos, 2003, págs. 439-452.

58 Así pudo comprobarse en un estudio anterior (Adela García Valle y Amparo Ricós Vidal, «Estudio filológico comparativo de documentación peninsular medieval. Las fórmulas jurídicas desde la fraseología histórica», Actas del XXIV Congreso Internacional de Lingüística y Filología Románicas (Aberystwith, 2004), t. II, Tübingen, Max Niemeyer Verlag, 2007, págs. 173-186). 
unidades fraseológicas propias de un contexto concreto, esto es, acaban adquiriendo categoría de locución adverbial por su forma y su significado. La lengua jurídica, por lo tanto, entendida como una tradición discursiva y textual, es determinante en el proceso de gramaticalización de la gran mayoría de las locuciones adverbiales estudiadas. De esta manera, a la observación de que las locuciones, al estar institucionalizadas sociolingüísticamente, «es posible adscribirlas a determinadas variantes geográficas o diastráticas $»^{59}$, hay que añadir que se pueden adscribir también a variantes diafásicas.

La tercera consideración permite señalar que, como ya pudo comprobarse a propósito de los documentos notariales, muchas de las locuciones adverbiales propias de la lengua jurídica que han pasado del latín al romance han transcendido finalmente a otros contextos. Y, aunque la presencia de locuciones en latín sigue siendo una de las características de los textos jurídicos de la época, tanto en los documentos redactados en latín, como en los escritos en romance, conviene señalar que en los fueros las locuciones latinas no son frecuentes, pues su presencia se reduce a los escritos en latín y aun así se presentan en contadas ocasiones. De hecho, se reduce el número casi exclusivamente a in pace, per forum, pro inde, etc. En cualquier caso, tal como se ha adelantado, la mayor parte de las locuciones encontradas tiene su precedente en latín, al igual que en el caso de las locuciones adverbiales que destacaban en los documentos notariales. De esta forma, el estudio demuestra que muchas de las locuciones adverbiales de la lengua jurídica proceden de su correspondiente latino.

La cuarta consideración afecta a las variaciones internas de las locuciones estudiadas. Estas variaciones se centran, a simple vista, en la presencia o ausencia de determinantes: por (su/este) fuero, por (la/su) fuerza, sin (su) grado, por (su) cabo, de pielpor el pie, etc. No obstante, el análisis de la variación interna de las locuciones forales pone de manifiesto que el elemento de variación más relevante es la alternancia de preposiciones para una misma locución: por/en/a fuero, porlalcon fuerza, porlalcon derecho, a/de yuso, a/de suso, porla bien, en/por tal guisa, alde vuelta, a/con buena fe, de/por el pie, a/en su vez, con/a verdad, etc. Esta alternancia de preposiciones no solo no conlleva cambios de significado, sino que es una muestra del proceso de consolidación tendente a la fijación final de las preposiciones en las locuciones; tendencia que ya observó $\mathrm{R}$. Lapesa a propósito de algunas fórmulas como de grado, mal grado y grado $a^{60}$, que son antecedentes de locuciones preposicionales.

Ahora bien, en este punto destaca igualmente una clara diferencia entre las locuciones de los fueros y las de los documentos notariales con respecto a la alternancia de preposiciones para una misma locución adverbial. Ciertamente, a

\footnotetext{
59 Joan M. Contreras, y Avel·lina Súñer, «Los procesos de lexicalización», art. cit., pág. 107.

${ }^{60}$ Rafael Lapesa, «Los casos latinos: restos sintácticos y sustitutos en español», Estudios de morfosintaxis histórica del español, t. I, Madrid, Gredos, 2000 [1962], págs. 112-113.
} 
las locuciones señaladas arriba, caracterizadas por alternar la preposición que las introduce sin variar el significado del complejo sintáctico, hay que añadir otro grupo de locuciones adverbiales en las que la alternancia de preposición conlleva un evidente cambio semántico, por ejemplo en el caso de en arriba 'cantidad', frente a a arriba 'lugar', 'cantidad' y 'tiempo', sin grado 'sin voluntad, sin gusto', frente a de/a grado 'por propia voluntad', por (su) cabo 'por su parte' frente a de cabo 'finalmente', etc. Esta característica se ha apreciado únicamente en los textos forales, no en los notariales.

Asimismo, es relevante el hecho de que algunas locuciones adverbiales no presenten variación alguna, sino que «muestran desde antiguo solidaridad entre la preposición y el elemento nominal, fijada idiomáticamente desde sus primeras documentaciones» ${ }^{61}$. En este estudio puede observarse en el caso de locuciones como en buena ventura, por ende, a sabiendas, de manifiesto, a mano, a medias, de nиеvo...

\section{CONCLUSIONES}

A partir de los ejemplos presentados y de las diferentes precisiones realizadas, pueden señalarse las conclusiones que se derivan del estudio de las locuciones adverbiales en los fueros, las cuales, además, marcan las semejanzas o diferencias que se aprecian entre los textos notariales y los forales. Son las que siguen a continuación:

En primer lugar, el análisis llevado a cabo ha permitido generalizar algunas de las conclusiones a las que pudo llegarse tras estudiar las locuciones adverbiales en los documentos notariales medievales. Con este análisis ha sido posible conocer las primeras fases del proceso de gramaticalización (fijación y desmotivación) de algunas locuciones y el enfrentamiento entre las distintas variantes de una misma locución para imponerse. Pues bien, en los textos jurídicos en general se aprecia claramente la pugna que se establece entre diferentes variantes de una misma locución. Puede observarse en los distintos tipos de variaciones, a saber, en cuanto a la preposición (a/con buena $f e . .$.$) , en cuanto al$ determinante (por la/su fuerza...) e incluso en la alternancia entre la variante que se presenta con determinante y la que no lo lleva ( $\sin (s u)$ grado...). M. T. Echenique constata, igualmente, la conmutación de preposiciones que en muchas ocasiones no altera el significado de la locución y que es una «muestra clara de la conexión existente entre fijación, por una parte, y proceso de consolidación de las preposiciones en las locuciones y en la sintaxis libre, por otra» ${ }^{62}$.

$61 \mathrm{M}^{\text {a }}$ Teresa Echenique, «Notas de sintaxis histórica en el marco del corpus de diacronía fraseológica del español (DIAFRAES)», en Stark, Schmidt-Riese y Stoll, eds., Romanische Syntax im Wandel, Tübingen, Gunter Narr Verlag, 2008, págs. 392-393.

${ }^{62}$ M. $^{\text {a }}$ Teresa Echenique, «Algunas notas sobre latín y romance», art. cit., pág. 544. 
La historia individual de cada locución desvela el proceso por el que se impuso una de entre las varias soluciones. Resulta necesario considerar todas estas variaciones, puesto que en los estudios sobre gramaticalización en español ha de atenderse no sólo a los «procesos consolidados finalmente en el uso», sino también «a los cambios que, habiendo existido en el pasado, no han llegado a imponerse en la lengua general» ${ }^{63}$.

Aportaciones previas a ésta, sobre las locuciones en los primeros textos romances en el ámbito peninsular, permitieron establecer una periodización en las locuciones al señalar una primera etapa romance en la que alternaron las formas latinas con sus correspondientes romances, y en la que los sintagmas locucionales, introducidos por preposición, actuaban como moldes para expresar los valores modales, temporales y espaciales principalmente ${ }^{64}$. Este análisis de los textos forales lo confirma y permite considerar una etapa común a las diferentes scriptae peninsulares en cuanto a las locuciones adverbiales propias del lenguaje foral $^{65}$.

En segundo lugar, hay que destacar que casi todas las locuciones de los fueros se presentan en romance, sin apenas alternancia con sus variantes latinas, a diferencia, de nuevo, de los textos notariales, en los que, si bien dominan las locuciones en romance, también aparecen muchas de ellas en latín (bona fide / en buena fe, in pace / en paz, etc.), incluso en los textos redactados en romance, como si de fórmulas jurídicas se tratara. Es decir, de la misma manera que los escritos notariales en romance presentan fórmulas latinas, recogen, igualmente, locuciones adverbiales en latín con más asiduidad que los fueros en los que, tal vez debido a lo reducido de la parte formularia, dominan casi exclusivamente las locuciones adverbiales en romance. Son pocas, pues, las locuciones de los fueros en latín, a saber, in pace, per forum, pro inde..., y algunas sólo presentan una apariencia gráfica latina (in paze, por inde, per foro...) que per-

63 M. ${ }^{\text {a }}$ Teresa Echenique, «Notas de sintaxis histórica...», art. cit., pág. 388.

64 Adela García Valle y Amparo Ricós Vidal, «Estudio filológico comparativo de documentación peninsular medieval...», art. cit.

65 Ahora bien, dado que algunas locuciones sólo aparecen en determinados fueros, podría pensarse en una posible diferenciación dialectal. Sin embargo, no se trata de un número considerable de locuciones y, además, no resulta oportuno basarse en las locuciones que se presentan en un único fuero para establecer estas diferencias. Así pues, sólo se encuentra en textos castellanos la locución en/a arriba (Madrid y Alcalá), así como dende adelante, dende arriba, con/a verdad y de sol a sol (Alcalá y Úbeda). Igualmente se aprecia un contraste entre estos dos últimos fueros y los leoneses en cuanto a dos locuciones. La primera es de cabo (Alcalá y Úbeda) frente a por cabo (Salamanca y Ledesma) con preposiciones y significados diferentes. La segunda es de/a grado (Alcalá y Úbeda), frente a sin grado (Salamanca y Ledesma, además de Alcalá), también con preposiciones y significados distintos. Y, finalmente, se presenta tan sólo en fueros leoneses la locución a/de vuelta (Salamanca y Ledesma). Quizá estas diferencias se deban al carácter castellano o leonés del texto, pero el número tan reducido de ejemplos no permite sostener esta afirmación sin basarla en un detenido estudio lingüístico de cada uno de los textos. 
mite considerarlas como arcaísmos en la escritura. Ahora bien, no habría que descartar la posibilidad de que la escasa presencia de locuciones adverbiales latinas en los fueros pudiera deberse a las fechas de redacción algo más tardías en la mayoría de ellos. Aún es más, prácticamente todas las locuciones en latín se concentran en el Fuero de Madrid, tal vez por ser el más antiguo y de escritura más arcaizante. Ello podría justificar asimismo en los fueros la falta de alternancia de las formas romances con las latinas, en comparación con la documentación notarial analizada ${ }^{66}$.

En tercer lugar, en el estudio de las locuciones presentes en los fueros, puede señalarse que la oralidad parece imponerse a la escritura, entendiendo por esto la presencia de un registro más coloquial en el caso del lenguaje foral. Posiblemente ésta sea la razón de que se evite recurrir a locuciones en latín, y se prefiera casi siempre las romances como a sabiendas, a verdad, por bien, etc. De esta manera, se ratifica la información que se desprende de los datos extralingüísticos, a los que se hacía referencia más arriba, y que algunos editores de los fueros señalaban, relacionados con la más que probable intervención de la tradición oral, de las fazañas, etc., en la redacción de los fueros. Coinciden, pues, los datos lingüísticos, que redundan en la marcada oralidad patente en los fueros, con los extralingüísticos, esto es, con todos aquellos aspectos históricos, sociales..., que envuelven la redacción de los textos forales.

En cuarto lugar, se observa que dominan, al igual que en la documentación notarial, las locuciones adverbiales modales. Ello se debe a que en el lenguaje jurídico se impone la expresión de la modalidad en los diferentes tipos de actuación jurídica (redacción de leyes, actos de escrituración, etc.). Algunas de estas locuciones están presentes también en la documentación notarial.

Por otro lado, las locuciones temporales no son muy frecuentes, destacan exactamente las mismas que en los documentos notariales. Por consiguiente, coincide de nuevo en esto la lengua foral con la notarial, a pesar de que en el caso de los fueros no aparecen apenas fórmulas con expresiones temporales que parecían sustituir a las locuciones adverbiales de tiempo en los documentos notariales. Por lo tanto, puede decirse, de una forma general, que las locuciones temporales no tienen la misma presencia en el lenguaje jurídico que las locuciones modales ${ }^{67}$.

$66 \mathrm{Y}$, aunque no pueda verse en el caso que nos ocupa, ya que todas las locuciones latinas o con apariencia latina del corpus eran ya sintagmas prepositivos en latín, conviene tener bien presente que «sustituir la construcción latina por otra con preposición es procedimiento románico, en el que hay etapas intermedias de convivencia con o sin preposición (como resto sintáctico, en este último caso)» (M. ${ }^{a}$ Teresa Echenique, «Notas de sintaxis histórica...», art. cit., pág. 393).

${ }^{67}$ De la misma opinión es A. Ricós, tras analizar los textos notariales portugueses de los siglos XII y XIII (Amparo Ricós Vidal, «As locuções adverbiais nos inícios da escrituração romance», II Congreso de Lusitanistas del Estado Español (Barcelona, Universitat de Barcelona, 2006). 
Además, las locuciones adverbiales que en los escritos notariales se utilizaban preferentemente como adverbiales de lugar, en los fueros se utilizan también para expresar otros valores como el de cantidad, por ejemplo. Se trata de casos como de suso, de yuso, dende arriba..., utilizados para asuntos pecuniarios o de cantidad en general.

En quinto lugar, también ha sido posible comprobar algunos de los procedimientos más productivos a la hora de crear locuciones adverbiales. Nos referimos sobre todo a la anteposición de la preposición en o incluso del adverbio dende a algunos adverbios en casos como en/dende arriba, en/dende a yuso, etc.; asimismo, la anteposición de una preposición a un elemento nominal, generalmente en masculino singular: por derecho, de su grado, por cabo, en alto, en ancho, de pie, a tuerto, en orden, por corazón, de nuevo, de diestro...; e igualmente empieza a notarse la presencia de un sintagma introducido por la preposición $a$, cuyo núcleo aparece en femenino plural, en locuciones tales como a sabiendas, a sueltas, a osadas, a medias ${ }^{68}$, etc.

Y, por último, en el caso de algunas locuciones adverbiales halladas, ha sido posible presentar su historia particular, rastreando el principio de sus apariciones e indagando en la evolución que han ido mostrando a lo largo del tiempo hasta llegar a la forma actual. Se trata entre otras de locuciones como de cabo, que parece haberse convertido en de cabo a rabo; de diestro y de siniestro que acabarán convirtiéndose en a diestro y siniestro; a tuerto y a derecho que llegarán a la locución a tuerto o a derecho, etc. Todas ellas son locuciones complejas formadas a partir de locuciones simples engarzadas, en las que la pérdida de motivación ha originado un sentido figurado, reforzado por aliteraciones, rimas o fórmulas apofónicas.

Analizada la presencia, uso y evolución de las locuciones adverbiales en los fueros medievales, queda de manifiesto, pues, la importancia que la lengua jurídica tiene en el estudio fraseológico en general y en el análisis de las locuciones adverbiales en particular.

${ }^{68}$ Ya en estos ejemplos se aprecia uno de los moldes que resultarán muy productivos en la creación de locuciones adverbiales, según Contreras y Súñer, quienes explican, además, «la fijación del femenino sin ningún contenido gramatical», al igual que «el uso de un plural vacuo, que no alterna con el singular correspondiente» («Los procesos de lexicalización», art. cit., pág. 91). 